\title{
MODA E CONSUMO: o design e a obsessão feminina por calçados
}

\section{FASHION AND CONSUMPTION: the design and the female obsession for shoes}

\author{
Samantha Grasielle Camara Pimentel, especialização em Ergonomia, UFPE \\ (samanthacpimentel@hotmail.com) \\ Ademario Santos Tavares, mestrando em Design, UFPE \\ (ademariojr@hotmail.com) \\ Rafaela Queiroz de Barros, mestranda em Design, UFPE \\ (queirozdebarros@hotmail.com) \\ Marcelo Márcio Soares, Ph.D., UFPE \\ (marcelo2@nlink.com.br)
}

\begin{abstract}
Resumo: Este trabalho tem por finalidade apresentar o paradoxo existente entre mulheres e sapatos. Apresenta a influência da moda, no contexto do consumo exacerbado pelo novo, onde tenta evidenciar a diferenciação social por meio do fetiche. Neste contexto, uma indústria de calçados necessitou desenvolver um novo sapato que atenda a demanda de mercado para este tipo de produto. $\mathrm{O}$ artigo abordará não somente as questões subjetivas ligadas a moda e ao fetiche, mas também todo o processo de desenvolvimento do produto. Mais do que os aspectos de consumo relacionados com o desejo do consumidor por status e diferenciação, o artigo irá descrever as questões técnicas relacionadas aos calçados, fazendo uma ponte entre o desejo simbólico e estético e a projeto técnico e prático.
\end{abstract}

Palavras-chave: Sapatos, Moda, Consumo, Design de Produto.

\begin{abstract}
Abstratc: This work aims to present the paradox between women and shoes. It introduces the influence between fashion, in the context of consumption exacerbated by new, highlighting the social differentiation through the fetish. In this context, a footwear industry had developed a new shoe which attend the market demand. This paper will address not only the subjective questions related to fashion and fetish, but in addition the entire product development process. More than aspects related to consumer desire for status and differentiation, this paper will describe the technical issues related to footwear, making a bridge between the symbolic and aesthetic desire and the technical and practical design.
\end{abstract}

Keywords: Shoes, Fashion, Consumption, Product Design. 


\section{INTRODUÇÃO}

Vivemos em uma sociedade de constantes diferenças sociais, econômicas, éticas, ideológicas, culturais e educacionais. Nesta miscelânea de diferentes sentimentos e escolhas está inserida a moda e a busca incessante pelo consumo de produtos, que ajuda a explicar a existência do próprio ser humano.

O ser humano, ao longo da história, sempre buscou se diferenciar dos demais, principalmente no que se refere a posse de artefatos. Neste contexto encontra-se a roupa, que antigamente exercia a função de proteção contra situações climáticas. Contudo, na idade contemporânea, a roupa permite a valorização do ser humano e oferece poder e status ao usuário. $\mathrm{O}$ artefato ainda é elemento de estudo da moda em design. Conforme Treptow (2007), a moda é vista como fenômeno social ou cultural que consiste na mudança de estilo através da necessidade de conquistar ou manter determinada posição social. Nos primórdios a roupa era vista somente como um protetor corporal passando, com o correr do tempo, a ser sinônimo de status.

Neste sentido, em relação aos calçados, mais precisamente os sapatos, sabe-se que a humanidade permaneceu durante pouco tempo de pés descalços e sua evolução foi concomitante com a moda e a vestimenta (JACOBBI, 2005). Na sociedade moderna, o sapato tornou-se uma obsessão feminina possuindo funções tanto práticas, de proteção para os pés, quanto funções estéticas, relacionados a elegância. Isto levou a autoestima da usuária, permitindo que esta se sentisse maravilhosa ou sexy, chique ou esportiva. Desta maneira, observam-se indicativos, tanto subjetivos quanto objetivos, que identificam os desejos das consumidoras e alimentam a indústria da moda, uma atividade produtiva de alta rotatividade e de caráter efêmero. Ainda de acordo com Jacobbi (2005), o interessante é que os sapatos definem as pessoas para sempre. Enquanto Karwowski et.al. (2011, p.335) afirma que "a função de um sapato tem sido descrita como uma proteção para superfícies duras", Paschoarelli \& Menezes (2009) contrapõem essa afirmação dizendo que, além do aspecto funcional dos sapatos, esses produtos tornaram-se fundamentais no que se refere à moda.

Após uma abordagem teórica referente ao apelo da moda no desenvolvimento de produtos contemporâneos, este artigo apresentará os procedimentos de desenvolvimento do produto. O estudo elaborou a proposta da criação de um novo sapato procurando evidenciar os delírios de consumo de uma mulher de meia idade e sua obsessão por sapatos, tomando como base o fetichismo, que é um elemento que dialoga com a moda e suas tendências. Vale ressaltar que o termo fetiche ${ }^{1}$ adotado nesse artigo refere-se às características "mágicas e sobrenaturais" de um objeto material, ou seja, as características subjetivas de um produto, que neste caso se refere a um par de sapatos.

\section{O ATO DE CONSUMIR E O DESENVOLVIMENTO DE PRODUTOS}

$O$ ato de consumir chegou a uma dimensão que pode ser visto como a satisfação da necessidade de emulação dos outros, ou seja, a busca pelo prazer, a defesa ou a afirmação do consumidor de acordo com o status que o produto ao ser

\footnotetext{
${ }^{1}$ O termo "fetiche" foi obtido através de consulta no Dicionário Aurélio Básico da Língua Portuguesa (FERREIRA, Aurélio Buarque de Holanda. Dicionário Aurélio Básico da Língua Portuguesa. Rio de Janeiro: Lexikon, 2003)
} 
adquirido pode proporcionar ao usuário (TREPTOW, 2007). O uso deste artefato é observado como uma espécie de competição entre membros de uma sociedade na busca por um grau de distinção ou prestígio cada vez maior. Diante disto, o senso de identidade de um indivíduo não é mais claramente determinado por sua filiação, mas também por sua classe social ou status de certos grupos, sendo definida por seus gostos e desejo de consumo (SLATER, 2002).

Já que a moda pode ser vista como um veículo de comunicação social, pode-se dizer que esteja suprindo uma função muito mais importante do que apenas satisfazer as necessidades básicas do ser humano. Acabou sendo dimensionada de modo mais profundo, inserida em questões relacionadas à natureza da realidade e ao verdadeiro propósito da existência humana (CAMPBELL, 2006).

Observou-se que o consumo nos tempos modernos se relaciona diretamente com o fator psicológico e com a efemeridade de certas categorias de produtos que se alimentam das tendências que se modificam constantemente. Lembrando que são os consumidores quem determinam à existência de um determinado produto ligado a influência da moda através de suas preferências e do ato de compra.

No caso do calçado, esta peça do vestuário tem diversas conotações em sua importância na valorização como objeto de desejo. Embora dois dos principais valores que Ihe são atribuídos sejam o conforto e a segurança, com o tempo, a estética e o status foram agregados como elementos diferenciais de valorização. É importante informar que o calçado mencionado nesse artigo se trata de um par de sapatos de salto alto de uso cotidiano. Esta é a delimitação do tipo de sapatos. Não se refere a calçados masculinos muito menos calçados da categoria esportiva ou ligados a segurança do trabalho.

O sapato contemporâneo é um produto que já vem sendo analisado em nossa sociedade e um de seus principais atributos é o de ser um produto que busca a excentricidade feminina, ou seja, seu estilo extravagante. Desta forma, as tendências da moda "exigem" modificações regulares, fazendo com que sapatos para mulheres estejam sujeitos a alterações periódicas da moda (PHEASANT, 2003).

Sendo assim, é importante observar que a moda e o consumo de produtos se entrelaçam, gerindo manifestações sociais e afirmações diante da configuração de um novo artefato. O produto é atribuído como símbolo por um determinado tempo e após a recriação de um novo objeto, aquele modelo anterior perde o significado de novidade. Desta forma, o novo sapato move o ciclo natural do consumo. Neste sentido, as tendências da moda é que ditarão o tempo de vida de cada produto.

\subsection{Produto de moda: acessório de luxo, objeto de desejo}

A moda pode ser vista como o estudo da indumentária compreendido através da perspectiva estética. Estabelece-se por afinidade de gosto entre quem cria e quem a usufrui. Seu objetivo principal é proporcionar o prazer de desfrutar de sua criação e afirmação perante um conceito social através de fenômenos culturais, produtivos, midiáticos e de consumo (SORCINELLI, 2008).

O termo moda tem em seu significado o uso, o hábito e o estilo geralmente aceito de determinado gosto, ideia e capricho. Pode ser variável no tempo e resultante das influências do meio. Também pode ser entendido como "à maneira de", de forma coletiva e pode se referenciar como uma maneira mais específica no conhecimento de 
uma maioria (AVELAR, 2011). A autora ainda diz que compreender a moda, equivale a entender a dinâmica social de imitação, de especificação e de individualização.

Já para Lipovetsky (1989) a "moda é o novo grande dispositivo do luxo, ela deriva mais do consumo ostentatório e das mudanças econômicas do que da transformação do imaginário cultural". Ainda de acordo com o autor, a moda compreende a dinâmica social, desde o século $X V$, através de sua imitação $e$ especificação, passando a ser compreendida como algo mais ligado ao vestuário, onde então surge a indústria da moda.

A indústria cultural da moda usa imagens, signos e símbolos evocativos de sonhos, anseios, ambições e fantasias, sugerindo uma identidade ao consumidor. De acordo com as características do consumidor, surgem os produtos de prestígio, sendo considerados ótimos meios de criação de identidade (FAGGIANI, 2006). Segundo Avelar (2011), a moda é o primeiro elemento que marca a mudança comportamental do corpo, difundindo e exibindo-o através de elementos que moldam padrões no comportamento. Para Castilho (2002), a caracterização de moda "sobrepõe-se ao corpo" como suporte ideal e consolida nossos desejos e crenças. Já Slater (2002) diz que sendo a moda a consolidação de desejos e crenças, todos os elementos da cultura podem ser examinados através de uma linguagem determinada.

Para Steele (1997), Moda é "o filho predileto do capitalismo", ou seja, os consumidores adoram o poder a que são atribuídos aos objetivos particulares (ditos exclusivos), enfatizando a adoração supersticiosa pelos ídolos que os próprios consumidores construíram. É neste momento onde entra o fetiche como algo que se atribui poder sobrenatural e se presta culto. Segundo Slater (2002), "a ideia do fetichismo da mercadoria pode estender-se ao ponto não só de fazer com que o valor de troca econômico pareça uma propriedade natural da coisa em si, como também pode parecer toda série de valores sociais e culturais". De acordo com McCracken (2003), os bens de consumo de luxo, ajudam o indivíduo a contemplar a posse de uma condição, circunstância social e estilo de vida, permitindo a esses indivíduos um conjunto de posses, atitudes e oportunidades.

Segundo Lipovetsky (1989) os produtos "de luxo" sempre foram valorizados e procurados, mostrando sua constância e persistência de códigos de diferenciação social. O fato de serem consumidos por uma classe exclusiva, os produtos de luxo dão aos seus consumidores um status social e um atributo de diferenciação, manifestandose como símbolo de poder e satisfação (FAGGIANI, 2006). Paschoarelli e Menezes (2009) corroboram com essa ideia quando chamam atenção para os saltos altos nos calçados femininos, associados ao gênero, status, sensibilidade feminina e moda.

Neste sentido, os sapatos denotam idade, estado de espírito e desejos, sendo considerados pela maioria das pessoas contemporâneas como um produto especialmente importante até mesmo como o centro de suas vidas (CAMPBELL, 2006). Diante do exposto, este trabalho relaciona a moda com o consumo, focando na obsessão feminina por sapatos, e a necessidade de encontrar um novo sapato desenvolvido pela indústria calçadista que atenda ao desejo de consumo de luxo feminino, tendo características fetichistas.

No caso dos sapatos, estes possuem uma linguagem própria que estabelece padrões sociais e até sugerem interpretações das mais diversas (CALDEIRA, 2005), assim "os sapatos de saltos exercem um encanto poderoso para muitas pessoas" (STEELE, 1997). 


\subsection{Público alvo}

O público a que o produto se destina é formado por mulheres de meia idade, na faixa etária entre quarenta e sessenta anos. Embora o consumo de luxo seja contemplado por diferentes faixas de idade, o público de meia idade exerce uma forte contribuição nesse sentido pois, as mulheres estão no auge de suas carreiras, cada vez mais inseridas no mercado de trabalho, mais sociáveis, cultas e consumidoras, ou seja, com forte capacidade de consumo. As características a serem abordadas no novo projeto foram a contemporaneidade, o consumo de luxo, o fetichismo e a valorização das tendências de moda para o outono/inverno 2012. Por destinar-se ao público feminino, optou-se em desenvolver um sapato de salto alto. Afinal, a sedução pela altura de um salto pode conduzir a uma atração especial ao usuário (PASCHOARELLI \& MENEZES, 2009).

\section{PROCEDIMENTOS METODOLÓGICOS}

O estudo desenvolveu um novo produto através da metodologia de Löbach (2001), apresentada a seguir, que analisa um fato ou um problema e suas condições necessárias para o alcance da solução do mesmo. As fases de desenvolvimento do novo sapato foram estruturadas em quatro fases e vinte e cinco sub-fases e estruturadas da seguinte maneira:

Fase de Preparação: subfase 01 - Análise da necessidade; subfase 02 - Análise da relação social; $\underline{03}$ - Análise da relação com o ambiente; $\underline{04}$ - Desenvolvimento histórico; $\underline{05}$ - Análise do mercado; $\underline{06}$ - Análise da função; $\underline{07}$ - Análise estrutural; $\underline{08}$ Análise da configuração; $\underline{09}$ - Análise de materiais e processo de fabricação; $\underline{10}$ Patentes, legislação e normas; 11 - Análise de sistemas de produtos; 12 - Exigências para com o novo produto; 13 - Descrição das características do novo produto.

Fase de Geração: subfase 14 - Conceitos de design; 15 - Alternativas de solução; 16 - Esboços de ideias; $\underline{17}$ - Modelos.

Fase de Avaliação: subfase 18 - Escolha da melhor solução; 19 - Incorporação das características ao novo produto.

Fase de Realização e Solução do Problema: subfase 20 - Projeto mecânico; 21 Projeto estrutural; 22 - Configuração dos detalhes; $\underline{23}$ - Desenvolvimento de modelos; $\underline{24}$ - Desenhos técnicos e representação bi e tridimensional; $\underline{25}$ - Documentação do projeto e relatório.

A fase inicial (Preparação) levou em consideração a categoria do produto, suas características e os processos de produção do mesmo. Nesta fase é necessário compreender os materiais, maquinários, técnicas de confecção, acabamentos e demais elementos que fazem parte da produção de um sapato para um correto planejamento. Adaptar as necessidades do projeto e as particularidades desse segmento de mercado auxiliaram a focar o processo na temática calçadista, principalmente na geração de requisitos e parâmetros.

A fase de geração correspondeu aos conceitos de design, elaborados através da representação bidimensional com esboços e diversos desenhos. Nesta fase ocorreu o brainstorm para geração de ideais.

A terceira fase teve relação com a avaliação das melhores soluções encontradas na etapa anterior, onde se optou pela melhor alternativa através das melhores características funcionais e estéticas. 
A fase final, de realização e solução do problema proposto, foi à fase mais técnica, onde os profissionais da indústria de calçados tiveram intensa participação. As máquinas foram utilizadas para tornar o desenho da alternativa escolhida em um produto final. Também foram utilizados desenhos, porém mais técnicos e esquemáticos, voltados para os detalhes mais ligados ao processo produtivo.

\subsection{Procedimentos da pesquisa de campo}

A obtenção dos dados ocorreu através de pesquisas em eventos ligados a moda e ao calçado, entrevistas com profissionais da área e consumidores, além de pesquisa de campo através da Associação Brasileira de Empresas de Componentes para Couro, Calçados e Artefatos (ASSINTECAL). Dentre os eventos pesquisados, o Fórum de Inspirações 2012 foi o mais importante para esta pesquisa, pois nele foi lançado o Caderno de Tendências da Associação Brasileira de Empresas de Componentes para Couro, Calçados e Artefatos (ASSINTECAL, 2012). Este caderno inclui as principais pesquisas relacionadas com os materiais, cores, acessórios e demais elementos a serem trabalhados nas futuras coleções de sapatos.

\subsection{Fase de preparação (análise do problema)}

Esta etapa analisa inicialmente o público alvo consumidor, na qual são observadas mulheres com mais de quarenta anos com uma grande e crescente tendência de consumo (subfases 01 e 02 de Löbach). Neste sentido, as indústrias da moda procuram materializar seus desejos desenvolvendo produtos que possam atender suas necessidades físicas e psicológicas. Como o produto do estudo deve atender ao mercado de luxo, buscou-se avaliar as características de mulheres de média idade, independentes e pertencentes a uma classe social alta e com forte poder de compra. A Figura 1 mostra imagens relacionadas ao contexto do mercado de luxo, com objetos, símbolos, ícones, cores e experiências (subfases 03-05 de Löbach).

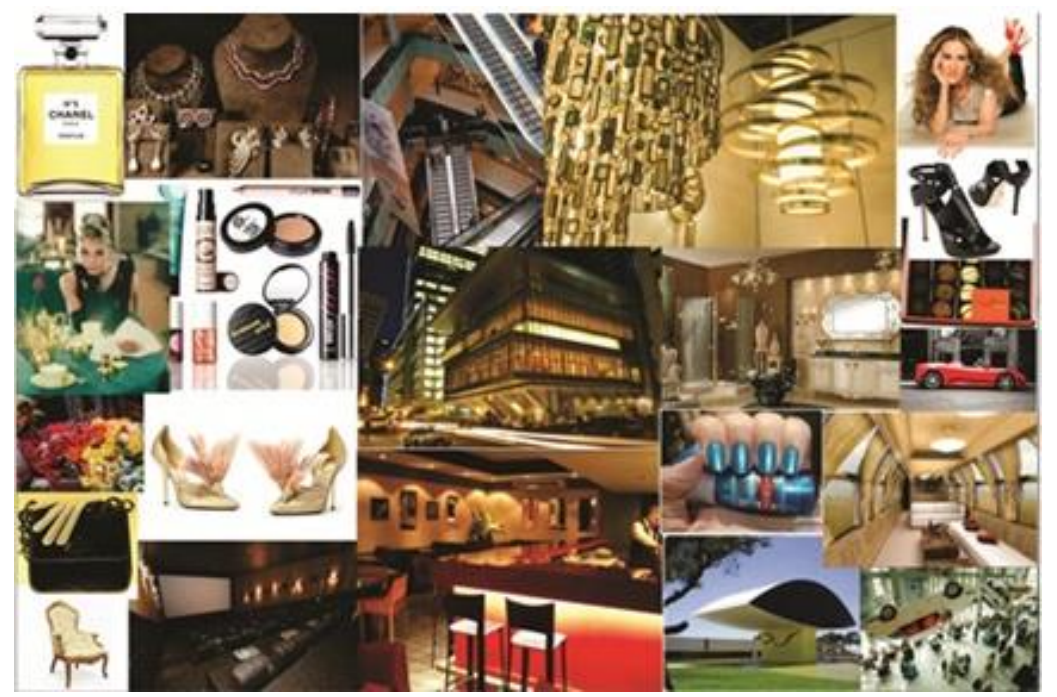

Figura 1 - Painel de público-alvo (fonte: Elaborado pela autora, com base na pesquisa realizada, com imagens obtidas no site Google, 2012)

Como ponto de partida foi imprescindível conhecer a estrutura de um sapato de salto alto. Conforme Karwowski et al. (2011), um sapato deve ser "aderente" ao pé em duas posições: na parte superior do peito do pé e em toda a parte traseira do 
calcanhar. Portanto, para conhecer as partes e elementos do tipo de sapato a ser desenvolvido, vários profissionais da indústria foram consultados. As disposições desses elementos podem fazer toda a diferença nos quesitos não apenas ligados à estética, mas principalmente no que se refere à segurança e ao conforto.

A Figura 2 procura evidenciar partes de um sapato de salto alto, indicando doze elementos distintos e que exercem diversas funções, desde fixação do sapato no pé até aderência do produto no piso.

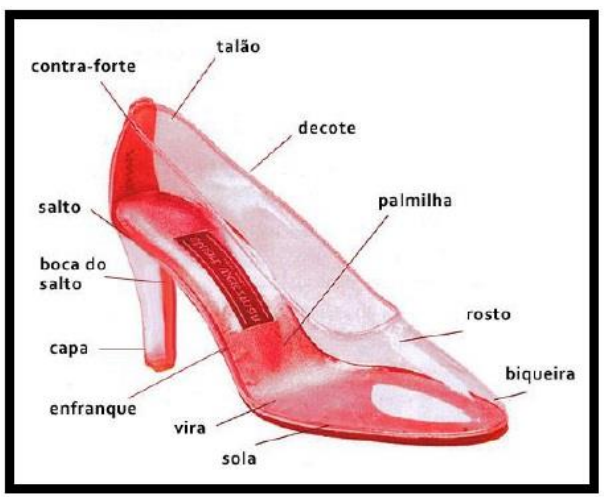

Figura 2 - Partes de um sapato feminino de salto alto (fonte: Adaptado de O’Keeffe, 1996)

Os aspectos de segurança e de conforto foram pesquisados (fases 06-09, 11). Conforme Attwood et al. (2004), para se obter um ajuste adequado ao corpo humano é importante conhecer detalhes sobre as dimensões do produto e do próprio corpo do usuário. Neste sentido, aspectos sobre antropometria também foram analisados, pois de acordo com lida (2005), os dados antropométricos são fundamentais para a adequação do produto ao usuário, especialmente em projetos de calçados.

Para Wickens et al. (2004), não é possível caminhar se os sapatos não atendem ao tamanho adequado. Já Karwowski (2001) afirma que um bom sapato deve ter uma boa palmilha que se molde ao pé, dando apoio através de uma área relativamente grande e, portanto, minimizando a pressão sobre a sola. Conhecer o encaixe do sapato no pé foi indispensável. Diversos testes de usabilidade foram feitos, inclusive com os materiais a serem utilizados, tanto no contato com o pé quanto no contato com o piso.

Um fator chave na segurança é a aderência da sola do sapato ao chão, que permite o caminhar do usuário, pois segundo Bridger (2003, p.181), o "atrito estático entre o sapato e o chão depende das propriedades de fricção e em área de contato". Anderson (2013) cita que o coeficiente de atrito representa a friç̧ão necessária para que o sapato possa permitir a locomoção humana em condições de superfícies secas.

São questões ligadas a segurança, afinal escorregões e quedas são regidos não somente por questões externas, de percepção humana, do controle da postura e equilíbrio, mas também pelas características de fricção do sapato (KARWOWSKI, 2001). Neste sentido, sapatos de salto alto são mais perigosos do que sapatos baixos (BRIDGER, 2003).

A Figura 3 apresenta as exigências do produto (subfase 12 de Löbach) que geraram requisitos e parâmetros. 
Figura 3 - Exigências (fonte: Elaborado pela autora, com base na pesquisa realizada, 2012)

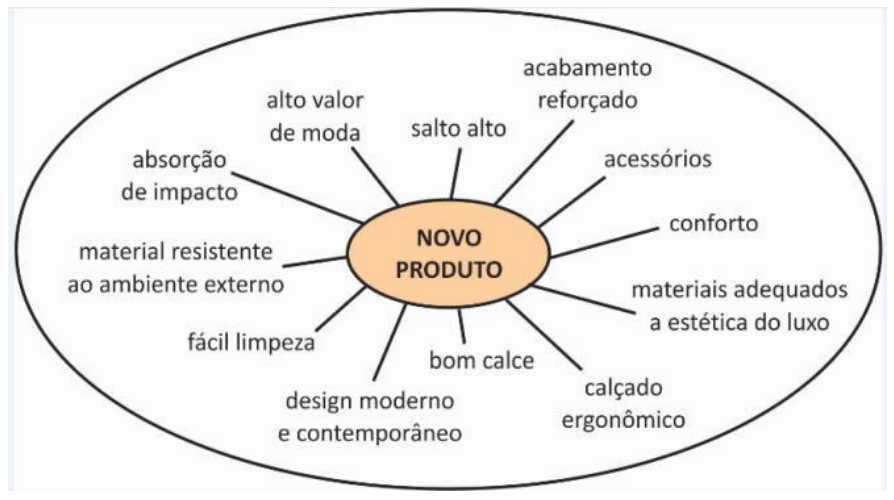

Para auxiliar e nortear os aspectos técnicos do projeto foram consultadas as normas técnicas brasileiras, especificamente aquelas relacionadas especificamente à indústria calçadista com o intuito de seguir as recomendações e especificações no que tange a segurança, o conforto, a construção, resistência e a qualidade desse tipo de produto. Na Tabela 1 são apresentadas as NBR`s que foram utilizadas durante o processo produtivo (sub-fase 10 de Löbach).

Tabela 1 - Normas utilizadas (fonte: Elaborado pela autora, com base na pesquisa realizada, 2012)

\begin{tabular}{lll}
\hline NBR & Ano & Construção inferior do calçado - Solas. solados e materiais afins - \\
\hline 14743 Ed2 & 2010 & $\begin{array}{l}\text { Determinação da resistência ao flexionamento por solicitações } \\
\text { contínuas }\end{array}$ \\
\hline 14837 & 2011 & Calçados - Determinação da temperatura interna do calçado \\
\hline 14838 & 2011 & Calçados - Determinação do índice de amortecimento do calçado \\
\hline 15171 & 2010 & Calçados - Determinação da resistência à flexão \\
\hline 15191 & 2012 & $\begin{array}{l}\text { Construção inferior do calçado - Saltos - Determinação da resistência à } \\
\text { fadiga, por impacto (Pica-Pau) }\end{array}$ \\
\hline 15377 & 2010 & Calçados - Determinação da resistência ao arrancamento de saltos \\
\hline 15838 & 2010 & $\begin{array}{l}\text { Calçados - Determinação da resistência à penetração de água com } \\
\text { máquina de flexão }\end{array}$ \\
\hline 16034 & 2012 & Determinação de conforto em componentes para calçados - Solados \\
\hline 16036 & 2012 & Determinação de conforto em componentes para calçados - Palmilhas \\
\hline 16037 & 2012 & Determinação de conforto em componentes para calçados - Forros \\
\hline
\end{tabular}

\subsection{Fase de geração (alternativas do problema)}

Esta etapa inicia o processo da fase de geração de alternativas. Para se estabelecer uma melhor definição da proposta para o público alvo foi escolhido um modelo de público a ser seguido em comum acordo com os membros da equipe de desenvolvimento de produto. Embora esta etapa tenha ocorrido na fase de análise do problema, sua utilização ocorreu neste momento de geração de alternativas.

Ficou definido que o ícone de público seria algumas personagens de seriado "Sexy and the City". Trata-se de um seriado norte americano exibido entre os anos de 1998 e 2004 que são apresentadas histórias sobre mulheres residentes na cidade de Nova lorque cercadas por cenários, diálogos e situações imaginárias, mas em especial pelo glamour das roupas, calçados e jóias, que são sinônimos de bom gosto e consumo de luxo. Embora seja um seriado fictício que evidencia o consumismo feminino por 
vestuário nos EUA, suas histórias possuem elementos que retratam com propriedade o atual cenário nacional, cujo mercado de luxo cresce vertiginosamente.

Tomando os devidos cuidados para o desenvolvimento de um sapato sem referenciar a cultura norte americana demonstrada no seriado, além de buscar trazer as cores, formas e elementos regionais, foi utilizado o Caderno de Tendências de 2012 (ASSINTECAL, 2012). Este material de referência possui diversos elementos vernaculares, tais como: palavras-chave, fatores sensoriais, tramas, texturas, padronagens, estampas, tabela de cores, cenários, croquis e diversas outras informações que auxiliem a compor um produto com características estéticas genuinamente brasileiras.

Diante do exposto, vale lembrar as características do produto a serem adotadas neste projeto: fetichismo feminino, mulheres de meia idade, apelo ao luxo e o uso de elementos contemporâneos. Dando sequência as atividades da geração de alternativas, as subfases seguintes (baseadas em Löbach) foram utilizadas: alternativas para solução do problema (15), esboço de ideias (16) e geração de modelos (17). Dentre as dezenas de alternativas geradas, oito foram escolhidas como adequadas para uma avaliação mais rigorosa. A figura 4 exibe as alternativas geradas.

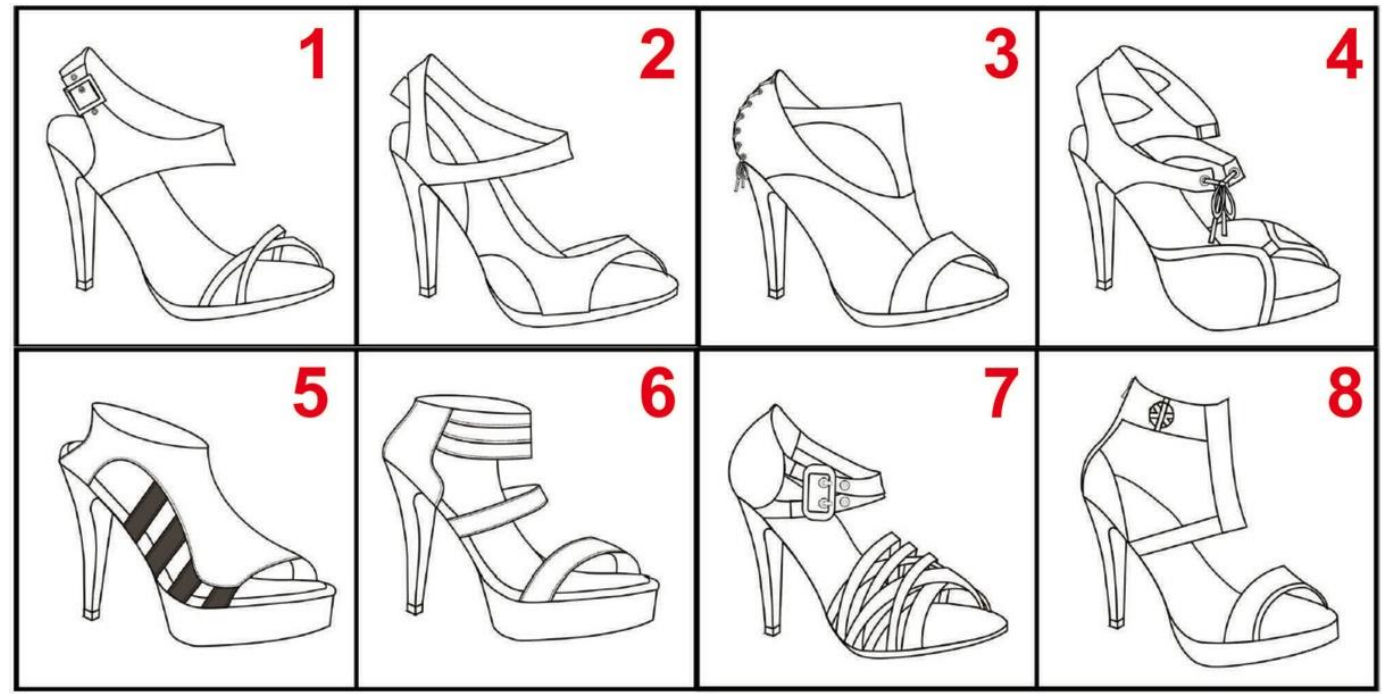

Figura 4 - Alternativas geradas no projeto (fonte: Elaborado pela autora, com base na pesquisa realizada, após processo de brainstorm, 2012)

\subsection{Fase de avaliação (avaliação das alternativas do problema)}

Para esta fase foi necessário desenvolver uma matriz de avaliação com o propósito de apontar a melhor proposta para a solução do problema, atendendo aos critérios e exigências básicas para com o novo produto.

Os requisitos adotados para esta matriz se basearam em fatores específicos adotados na produção de um calçado. Foram evidenciados não somente elementos estruturais como "material adequado", "resistência ao ambiente externo", "salto alto", "conforto", "ergonomia" (usabilidade), "acabamento reforçado". Mas também foram avaliados elementos ligados à moda e a estética do produto, como o "valor de moda" (concomitante com as tendências estudadas), "acessórios" (adornos no corpo do produto), "design moderno e arrojado", dentre outros.

O modelo a ser escolhido para o processo de prototipagem resultou da maior pontuação obtida, ou seja, o maior valor de acordo com os requisitos exigidos. A 
pontuação foi feita pelos diversos profissionais ligados a diversos setores de uma indústria de calçados, como designers, equipe de marketing, operadores de fabricação e montagem, setor de compras, e outros da área.

Desta maneira, procurou-se incluir no processo de desenvolvimento do produto todos os profissionais que estivessem relacionados com o produto e não apenas os responsáveis pela geração das ideias. Este processo participativo foi capaz de gerar um produto que permitisse uma produção que atendesse não somente aos desejos do público alvo, mas que respeitasse as limitações do setor produtivo da empresa.

O peso dos fatores da matriz de avaliação foram divididos em três níveis: 1 (pouco), 2 (médio) e 3 (alto). Já as notas foram divididas em cinco graus de satisfação: 1 (péssimo), 2 (ruim), 3 (regular), 4 (bom) e 5 (ótimo).

A matriz gerou o seguinte resultado para cada um dos modelos: Alternativa 1 (101 pontos); Alternativa 2 (109 pontos); Alternativa 3 (124 pontos); Alternativa 4 (128 pontos); Alternativa 5 (100 pontos); Alternativa 6 (107 pontos); Alternativa 7 (100 pontos); Alternativa 8 (114 pontos).

Observou-se que algumas alternativas tiveram pontuação muito próxima. Porém, a alternativa que obteve a maior pontuação foi a de número quatro. Portanto, esta foi a escolhida para o processo de prototipagem.

\subsection{Fase de realização (realização da solução do problema)}

O modelo de calçado escolhido mostra que além de uma forte função estética, diversas qualidades estruturais foram adotadas, tais como forro interno levemente espumado, meia pata alta embutida, o que diminui o desconforto intensificado pelo salto, palmilha levemente acolchoada dando maior conforto ao usuário. Estas questões são importantíssimas para que o produto possa atender as necessidades físicas e de usabilidade do público alvo, possibilitando conforto e segurança.

Porém, o sapato desenvolvido tem forte ligação com as tendências da moda e com o mercado de luxo. Nesse sentido, o caráter estético tem forte influência, pois suas formas buscam atrair a atenção do público alvo, evidenciando o fetichismo que esta peça do vestuário causa no público feminino. Produtos com esta estirpe evidenciam-se no mercado primeiramente pelas suas características estéticosimbólicas do que pelos aspectos funcionais, portanto a aparência é um elemento chave para o desenvolvimento de produtos.

A figura 5 mostra duas imagens do produto final. A esquerda está o desenho de apresentação com as cores definidas pela tabela de cores obtidas pelo Caderno de Tendências (ASSINTECAL, 2012). Este desenho em perspectiva mostra detalhes de elementos e acessórios, e permitirá que a equipe busque pelos materiais que atendam as suas formas e a combinação das cores.

Já a imagem da direita é o modelo final, ou seja, o protótipo em escala real (1:1) do sapato. Este protótipo foi testado pela equipe e atendeu aos requisitos da matriz de avaliação e aos objetivos propostos. É importante mencionar que este modelo final foi desenvolvido em um tamanho específico e servirá de base para outros tamanhos que possam atender ao público alvo e suas possíveis variações fisiológicas e antropométricas relacionadas ao tamanho dos pés. 


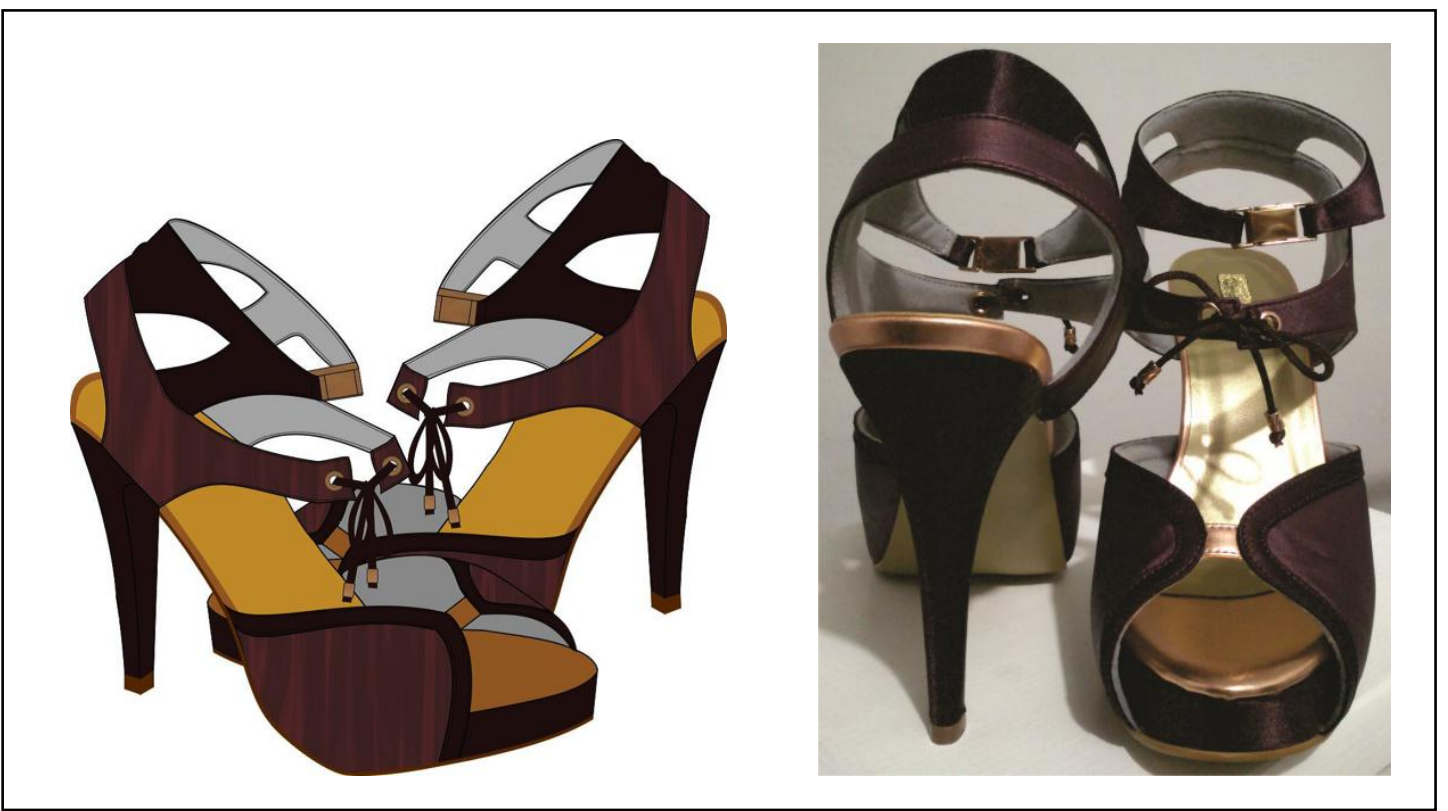

Figura 5 - Desenho de apresentação e protótipo finalizado (fonte: Elaborado pela autora, com base na pesquisa realizada, 2012)

\section{CONCLUSÃO}

Para a construção do novo sapato fez-se necessário a utilização de uma metodologia e pesquisas sobre o público-alvo em potencial do produto. Embora os objetivos tenham conceitos, questões, simbolismos e demais elementos oriundos da moda, que é uma área com forte apelo estético, de produção efêmera e carregada de muita subjetividade, os aspectos técnicos foram fundamentais para que o desejo do consumidor se materializasse em um produto final.

Portanto, foi necessário entender o calçado não somente como produto proveniente da moda, com função simbólica de status social elevado e acessório de luxo como objeto de desejo. Mas compreendê-lo como uma peça de vestuário de grande utilidade no cotidiano, seja no lazer ou no trabalho, um objeto que exerce a função de interface entre os pés do usuário e o piso do ambiente. É importante ressaltar que se trata de um produto industrial e/ou artesanal passível de produção em larga ou pequena escala e conforme lida (2005), é uma peça que precisa apresentar características ergonômicas independente da variedade de tipos e modelos.

Outro fator de grande relevância tem a ver com o atendimento das premissas técnicas presentes nas etapas de desenvolvimento de produtos, embora os objetivos deste estudo tenham sido pautados também na estética do produto. $O$ aspecto visual é um elemento fortíssimo, um verdadeiro "vendedor oculto" que encanta os olhares e auxilia o processo de venda, porém as questões técnicas são fundamentais para que o produto possa ser utilizado com segurança e conforto.

\section{REFERÊNCIAS}

ANDERSON, Martin. Contemporary Ergonomics and Human Factors, Institute of Ergonomics \& Human Factors. Proceedings. CRC Press, 2013.

Associação Brasileira de normas técnicas. ABNT. 2011. Disponível na internet por http em: <http://www.abnt.org.br>. Acesso em: 10 abril 2012. 
ATTWOOD, Dennis A.; DEEB, Joseph M.; DANZ-REECE, Mary E. Ergonomic Solutions for the Process Industries. Elsevier, 2004.

Associação Brasileira de Empresas de Componentes para Couro, Calçados e Artefatos, ASSINTECAL, 2012. Disponível na internet por http em: <http://ww3.assintecal.org.br/ forum/content/conteudos/?id=1>. Acesso em: 15 maio 2012.

AVELAR, Suzana. Moda, Globalização e Novas Tecnologias. 2 Ed. São Paulo: Estaçao das Letras, 2011.

BRIDGER, R. S. Introduction to Ergonomics. Taylor \& Francis, 2003.

CALDEIRA, Gabriela de Castro Novais. Os sapatos ao longo da existência humana e sua contemporaneidade. Postado em 2005. Disponível na internet por http em: <http://www.antennaweb.com.br/edicao2/artigos/pdf/artigo4.pdf>. Acesso em 25 abr. 2012.

CAMPBELL, Colin; BARBOSA, Lívia. Cultura de Consumo e Identidade. Rio de Janeiro: Editora FGV, 2006.

CASTILHO, Kátia; GALVÃO, Diana. A moda do corpo, o corpo da moda. São Paulo: Editora Esfera, 2002.

FAGGIANE, Katia. O Poder do Design - Da Ostentação à Emoção. Brasília: Theasaurus, 2006.

IIDA, Itiro. Ergonomia - Projeto e Produção. São Paulo: Edgard Blücher, 2005.

JACOBBI, Paola. Eu quero aquele Sapato! Tudo sobre uma Obsessão Feminina. Rio de Janeiro: Editora Objetiva, 2005.

KARWOWSKI, Waldemar (ed.). International Encyclopedia of Ergonomics and Human Factors. Vol. 1, Taylor \& Francis, 2001.

KARWOWSKI, Waldemar; SOARES, Marcelo M.; STANTON, Neville A. (Ed.) Human Factors and Ergonomics in Consumer Product Design - Methods and Techniques. CRC Press, 2011.

LIPOVETSKY, Gilles. O império do efêmero: a moda e seu destino nas sociedades modernas; tradução Maria Lúcia Machado. - São Paulo: Companhia das Letras, 1989.

LÖBACH, Bernd. Design Industrial: bases para a configuração dos produtos industriais / Tradução Freddy Van Camp - São Paulo: Editora Blucher, 2001.

MCCRACKEN, Grant. Cultura e consumo: Novas abordagens ao caráter simbólico dos bens e das atividades de consumo. Tradução: Fernanda Eugênio. Rio de Janeiro: Mauad, 2003.

PASCHOARELLI, Luis Carlos; MENEZES, Marizilda dos Santos (org). Design e ergonomia: aspectos tecnológicos. São Paulo: Cultura Acadêmica, 2009

SLATER, Don; tradução de Dinah de Abreu Azevedo. Cultura do Consumo e Modernidade. São Paulo: Editora Nobel, 2002.

SORCINELLI, Paolo (organizador); Alberto Malfitano, Giampaolo Proni, colaboradores: Renato Ambrosio, tradutor. Estudar a moda: corpos, vestuários, estratégias. São Paulo: Editora Senac, 2008.

STEELE, Valerie. Fetiche: Moda, Sexo e Poder. Tradução Alexandre Abranches Jordão. Rio de Janeiro: Rocco, 1997.

TREPTOW, Doris. Inventando Moda: Planejamento de Coleção. 4. ed. Editora Brusque, 2007.

WICKENS, Christopher D.; LEE, John; LIU, Yili; BECKER, Sallie Gordon. An Introduction to Human Factors Engineering. 2 ed. Pearson Prentice Hall. 2004. 